\title{
A Restrictive Blood Transfusion Strategy and Patient Blood Management Improved Clinical Outcomes in Cardiac Surgery Patients
}

\author{
Sajad Yarahmadi (iD) ${ }^{1,}$, Hassan Najafizadeh ${ }^{2}$ and Hassan Teimouri ${ }^{2}$ \\ ${ }^{1}$ Nursing Care Research Center, Semnan University of Medical Sciences, Semnan, Iran \\ ${ }^{2}$ Social Determinants of Health Research Center, Lorestan University of Medical Sciences, Khorramabad, Iran \\ "Corresponding author: Social Determinants of Health Research Center, Lorestan University of Medical Sciences, Khorramabad, Iran. Email: s.yarahmadiooo@gmail.com \\ Received 2021 March 16; Accepted 2021 April 20.
}

Keywords: Blood Transfusion, Blood Management, Cardiac Surgery

\section{Dear editor,}

Anemia is common among patients undergoing cardiac surgery (1). Acute anemia and red blood cell (RBC) transfusion followed by increased mortality are common among cardiac surgery patients (2). Dealing with anemia and blood transfusion is always a challenge for health professionals, especially in intensive care units. Several retrospective studies have indicated an association between the transfusion of blood products and mortality (3-5). In addition, several randomized clinical trials have revealed lack of superiority of a liberal transfusion strategy to a restrictive strategy in surgical $(5,6)$ and gastrointestinal bleeding patients (3). Although it has not been clearly established that blood transfusion has adverse effects, Bradford Hill criteria strongly suggest causation (7). On the other hand, preoperative anemia or blood loss during or after surgery are associated with adverse effects and are powerful predictors of RBC transfusion (8). Recently, patient blood management has been introduced as a preventive strategy to minimize the possibility of RBC transfusion as an emergency treatment for anemia. Three of the main pillars of patient blood management include identifying and treating anemia and iron deficiency before surgery, minimizing blood loss, and a restrictive blood transfusion strategy (9). The present letter demonstrates the benefits of a restrictive transfusion strategy for patients undergoing heart surgery.

Transfusion and hemoglobin level: In a restrictive transfusion strategy, patients' hemoglobin levels were lower than those of patients in a liberal strategy group (10). However, it was observed in a study by Jehovah that mean hemoglobin at discharge in those who did not receive blood transfusion was higher in comparison with matched controls (11.7 g/dL vs. $9.8 \mathrm{~g} / \mathrm{dL}$ ). None of the Jeho- vah's participants received a transfusion of RBC, although $67.8 \%$ of control patients were administered at least one transfusion of RBC (11). In another study, using a restrictive transfusion strategy, RBC transfusion rate was decreased from 39.3 to $20.8 \%$. Also, the transfusion index (amounts of units of RBC, FFP, and PLT transfused per patient) was reduced significantly. Following the implementation of the patient blood management program, the rate of blood transfusion decreased. In addition, discharge hemoglobin level increased in cardiac surgery patients (12).

Hospital mortality: There was no difference in the mortality rate between the two liberal and restrictive transfusion strategies (10-13). However, a study reported that the mortality rate in the restrictive strategy group was lower than that in the liberal strategy group (14).

Acute renal failure: In previous studies, no difference in acute renal failure between the liberal and restrictive transfusion strategies has been noted $(3,10,11,15)$. However, following a complete patient blood management program could diminish the rate of acute renal failure. The occurrence of postoperative acute renal failure declined in the patient blood management period from 7.6 to $5.0 \%$ (12).

Hospital stay: The duration of hospitalization could be reduced by implementing a patient blood management program. In the study of Gross, hospital stay decreased from a mean of 12 days to 10 days (12). Also, studies show no difference in the length of hospital stay between the restrictive and liberal blood transfusion strategies $(5,11)$.

Costs: In the study of Gross, by implementing a patient blood management program, total direct costs decreased by a mean of 4,000\$ (12). In another study, cost reduction was observed following the implementation of a restrictive blood transfusion strategy (11).

Other side effects: The incidence of stroke remained 
unchanged by implementing patient blood management and using restrictive strategy blood transfusion $(12,15)$. In the study of Nakamura, the incidence rates of cardiogenic shock and acute respiratory distress syndrome were similar in the restrictive and liberal transfusion groups. However, in older patients, cardiogenic shock was more common in the restrictive transfusion group (10). A study showed that the restrictive strategy did not have a significant effect on the risk of infection (15). Another study indicated that no infectious complication was observed in any of patients in the restricted strategy group during hospitalization, while one infectious complication was observed in $7.8 \%$ of the patients in the liberal strategy group (11).

In conclusion, various studies have provided evidence in support of the use of a restricted blood transfusion strategy (11-16). The implementation of patient blood management and restrictive strategy blood transfusion can reduce the incidence of renal failure, duration of hospitalization, and costs. In addition, there is no difference in the implementation of a restrictive or liberal blood transfusion strategy in terms of other clinical outcomes. Therefore, it is recommended for health professionals to use a restrictive strategy of blood transfusion and patient management to correct anemia in cardiac surgery patients.

\section{Acknowledgments}

The authors sincerely thank Miss Tayebeh Cheraghian for translating this letter from Persian to English.

\section{Footnotes}

Authors' Contribution: SY contributed to study design and manuscript writing; HN contributed to the acquisition of data; HT contributed to the drafting of the manuscript.

Conflict of Interests: The authors declare that they have no competing interests.

Funding/Support: None to declare.

\section{References}

1. Jakobsen CJ, Ryhammer PK, Tang M, Andreasen JJ, Mortensen PE. Transfusion of blood during cardiac surgery is associated with higher long-term mortality in low-risk patients. Eur J Cardiothorac Surg. 2012;42(1):114-20. doi:10.1093/ejcts/ezr242. [PubMed: 22241009].

2. Khanna MP, Hebert PC, Fergusson DA. Review of the clinical practice literature on patient characteristics associated with perioperative allogeneic red blood cell transfusion. Transfus Med Rev. 2003;17(2):110-9. doi: 10.1053/tmrv.2003.50008. [PubMed:12733104].
3. Villanueva C, Colomo A, Bosch A, Concepcion M, Hernandez-Gea V, Aracil C, et al. Transfusion strategies for acute upper gastrointestinal bleeding. N Engl J Med. 2013;368(1):11-21. doi: 10.1056/NEJMoa1211801. [PubMed: 23281973].

4. Karkouti K, Wijeysundera DN, Beattie WS; Reducing Bleeding in Cardiac Surgery Investigators. Risk associated with preoperative anemia in cardiac surgery: A multicenter cohort study. Circulation. 2008;117(4):478-84. doi: 10.1161/CIRCULATIONAHA.107.718353. [PubMed: 18172032].

5. Murphy GJ, Reeves BC, Rogers CA, Rizvi SI, Culliford L, Angelini GD. Increased mortality, postoperative morbidity, and cost after red blood cell transfusion in patients having cardiac surgery. Circulation. 2007;116(22):2544-52. doi: 10.1161/CIRCULATIONAHA.107.698977. [PubMed: 17998460].

6. Carson JL, Terrin ML, Noveck H, Sanders DW, Chaitman BR, Rhoads GG, et al. Liberal or restrictive transfusion in high-risk patients after hip surgery. N Engl J Med. 2011;365(26):2453-62. doi: 10.1056/NEJMoa1012452. [PubMed: 22168590]. [PubMed Central: PMC3268062].

7. Isbister JP, Shander A, Spahn DR, Erhard J, Farmer SL, Hofmann A. Adverse blood transfusion outcomes: Establishing causation. Transfus Med Rev. 2011;25(2):89-101. doi: 10.1016/j.tmrv.2010.11.001. [PubMed: 21345639].

8. Gombotz H, Rehak PH, Shander A, Hofmann A. Blood use in elective surgery: The Austrian benchmark study. Transfusion. 2007;47(8):146880. doi: 10.1111/j.1537-2995.2007.01286.x. [PubMed: 17655591].

9. Spahn DR, Moch H, Hofmann A, Isbister JP. Patient blood management: The pragmatic solution for the problems with blood transfusions. Anesthesiology. 2008;109(6):951-3. doi: 10.1097/ALN.0b013e31818e3d75. [PubMed: 19034088].

10. Nakamura RE, Vincent JL, Fukushima JT, de Almeida JP, Franco RA, Lee Park C, et al. A liberal strategy of red blood cell transfusion reduces cardiogenic shock in elderly patients undergoing cardiac surgery. J Thorac Cardiovasc Surg. 2015;150(5):1314-20. doi: 10.1016/j.jtcvs.2015.07.051. [PubMed: 26318355].

11. Guinn NR, Roberson RS, White W, Cowper PA, Broomer B, Milano $C$, et al. Costs and outcomes after cardiac surgery in patients refusing transfusion compared with those who do not: A case-matched study. Transfusion. 2015;55(12):2791-8. doi: 10.1111/trf.13246. [PubMed: 26183817].

12. Gross I, Seifert B, Hofmann A, Spahn DR. Patient blood management in cardiac surgery results in fewer transfusions and better outcome. Transfusion. 2015;55(5):1075-81. doi: 10.1111/trf.12946. [PubMed: 25565302].

13. Mazer CD, Whitlock RP, Fergusson DA, Belley-Cote E, Connolly K, Khanykin B, et al. Six-month outcomes after restrictive or liberal transfusion for cardiac surgery. NEngl J Med.2018;379(13):1224-33. doi: 10.1056/NEJMoa1808561. [PubMed: 30146969].

14. Mazer CD, Whitlock RP, Fergusson DA, Hall J, Belley-Cote E, Connolly $K$, et al. Restrictive or liberal red-cell transfusion for cardiac surgery. $N$ Engl J Med. 2017;377(22):2133-44. doi: 10.1056/NEJMoa1711818. [PubMed: 29130845].

15. Shehata N, Mistry N, da Costa BR, Pereira TV, Whitlock R, Curley GF, et al. Restrictive compared with liberal red cell transfusion strategies in cardiac surgery: A meta-analysis. Eur Heart J. 2019;40(13):1081-8. doi: 10.1093/eurheartj/ehy435. [PubMed: 30107514]. [PubMed Central: PMC6441852].

16. Willems A, Harrington K, Lacroix J, Biarent D, Joffe AR, Wensley D, et al. Comparison of two red-cell transfusion strategies after pediatric cardiac surgery: A subgroup analysis. Crit Care Med. 2010;38(2):64956. doi: 10.1097/CCM.0b013e3181bc816c. [PubMed: 19789443]. 